\title{
Gamification as the human resources management tool
}

\author{
Valeria Kanivets $^{1}$, and Yulia Beliaeva $^{2 *}$ \\ ${ }^{1}$ Department of Management and Rural Development, Federal State Budgetary Educational \\ Institution, Higher Education "St. Petersburg State Agrarian University" (St. Petersburg, Pushkin, \\ Russia) \\ ${ }^{2}$ Department of Foreign Languages and Speech Culture, Federal State Budgetary Educational \\ Institution, Higher Education "St. Petersburg State Agrarian University" (St. Petersburg, Pushkin, \\ Russia)
}

\begin{abstract}
There is a huge number of different methods created to increase employee motivation, while they are constantly being improved and new ones appear. The manager must not only choose the right one, but also be able to implement it. One of the methods is gamification. The basics of HR management processes using this method are just beginning to form, so it is necessary to develop mechanisms for implementing gamification in the organization. Based on the research, the main provisions aimed at including elements of gamification in the company and recommendations for their implementation are formulated. The purpose of the article is to study gamification in the organization's personnel management in detail and to formulate practical recommendations for its application. The research used methods of the theoretical level, such as: study and generalization, analysis and synthesis, deduction and induction, as well as the study of literature, the regulatory framework and other sources of information. On the basis of the study, the types of games and players, the main provisions aimed at including elements of gamification in the company, as well as recommendations for their implementation to improve the organization's activities are formulated.
\end{abstract}

In our age of competition in the market and the development of technologies, there are more and more new ways of motivating and managing personnel based on team building and a favorable environment in the team.

One of the modern methods of personnel management is gamification, which was proposed by N. Pelling in the early 2000 s.

Gamification is the use of approaches specific to computer games in non-game processes in order to attract people and increase their involvement in solving problems. Companies prefer role-playing games, quests, case-championships for team building, adaptation of beginners and other HR tasks. It is important to note that gamification is not a full-fledged game, but only some of its elements:

\footnotetext{
* Corresponding author: juliebeliaeva@yandex.ru
} 
- virtual rewards that encourage initiative;

- points;

- virtual currency;

- levels;

- ratings;

- interactive elements;

- quests.

Gamification is a very powerful tool for increasing staff motivation, especially if you take into account a number of principles when creating a game:

- competitive spirit;

- clarity of the rules for obtaining points and passing;

- separation of individual and group rankings;

- ability for participants to reward each other for useful social actions;

- interest of the game for participants;

- creating an additional version of the game for mobile devices;

- presence of a site with frequent updates and unusual content.

The expediency of using this tool is due to the "generational shift" in the structure of the labor force: there is an increase in the share of employees of the "Y" generation, and traditional management methods are not suitable for them [1].

The analysis of the practice of using gamification in personnel management in an organization allows us to distinguish three main types of games: managerial, functional and situational. The management game involves the participant performing the role of the head of the organization or structural unit. In functional games, a specific field of activity is considered. In situational games, employees gain skills in solving certain situations, such as how to resolve a conflict.

Gamification allows the manager to solve the following tasks:

- Modernization of personnel selection (the ability to use video resumes or another interactivity).

- Creating a faster and easier process of adapting new people (trainings, virtual excursions).

- Evaluation of the work of the staff (selection of the worthiest employees, depending on the number of points).

- Encouraging the desire for innovation (creating a playground where there is an opportunity to offer ideas for bonuses).

- Motivating employees (interactive courses, assigning points and stickers to the most active players).

- Improve training in general (webinars, interactive maps).

Determining the subject of the competition and the scoring system: this should be a clear and measurable metric: the number of attracted customers (to increase), the number of complaints from customers (to decrease), number of points earned for various actions (participation in events, generating ideas, etc.).

Creation of an accessible standings: the simplest thing, naturally, is within the Internet the information must be updated at least once a day, otherwise the interest in the game will fade. It is possible that a couple of days before the end of the competition, the standings are closed to give the laggards an incentive to make a breakthrough and surprise everyone.

Coverage of the course of the competition: to keep the interest in the contest alive, determine in advance who will talk about the interim results, how often and in what form. Whether it will be a general mail newsletter, news on the Internet, ads on the walls of the office are not of high importance, but the coverage should be regular and interesting — as a variant with interviews of leaders, forecasts, polls. 
Determining the prize pool: this must happen at the start; but if the budget is small, then in order not to devalue the game, the prize can be a surprise that remains a secret until the end of the game. But the prize must be significant.

Identification of insignis / awards/ badges: that will be permanently retained by employees and will be publicly available.

The award ceremony: solemnly, with a newsletter to all employees, with the participation of the company's top manager, interviews of the winners and a festive atmosphere.

Every supervisor and human resource specialist should keep in mind that awards should not be given too often and that the conditions for receiving them should not be simple or the same, as this devalues them. It will be much more pleasant for a person to get it for a difficult task, to gain it by their own work, and this will increase their motivation in the future.

After determining the types of gamers, you can move on to the next stage - this is to set a goal, that is, the results that we want to achieve and the time frame for achieving them, and then, in the process, keep records and monitor.

One should not forget about the implementation of the solution, business games and gameplay, for example, to think through the rules of the game yourself or find ready-made options, at the same time studying the experience of other companies, as well as to create a schedule and scenario of the process.

It is necessary to study not only the types of games, with their great amount, but also the players themselves, so now one of the classifications of both games and gamers will be presented.

The analysis of the practice of using gamification in personnel management in an organization allows us to distinguish three main types of games: managerial, functional and situational.

The managerial game involves the participant performing the role of the head of the organization or structural unit.

In functional games, a specific field of activity is considered.

In situational games, employees gain skills in solving certain situations, such as how to resolve a conflict.

Organizational-activity game is a kind of operational games, a form of active learning to solve problem situations by modeling cognitive research and organization of social and industrial activities. Therefore, another name for organizational activity games is the term problem-business ones.

Innovative games have two goals: removing negative attitudes towards actions to reorganize the activities of an organization (enterprise) and making constructive changes to the reorganization project itself.

Role-playing (or story-role-playing) is a special group of game methods, the participants of which act within the framework of their chosen roles, guided by the nature of their role and the internal logic of the action environment, and not by the external scenario of behavior.

A business game is an imitation of a working process, its simulation, a simplified reproduction of a real production situation. It is a sequence of actions that players must perform to achieve a certain result. The game is governed by the rules that are pre-written in the script.

Business games, in turn, also have their own classification according to the following characteristics:

1. by the time of the event:

- no time limit;

- with time limit; 
- real-time (on-line) games;

- games where time is compressed;

2. by performance evaluation:

- a point or other assessment of the player's or team's performance;

- there is no assessment of manner of work;

3. according to the final result:

- fixed games - the answer is known in advance (for example, the network schedule), there are strict rules;

- free / open games - there is no known answer in advance, the rules are invented for each game, the participants work on solving an unstructured problem;

4. according to the final goal:

- training - aimed at the revealing of new knowledge and strengthening the skills of participants;

- ascertainers - professional skill competitions;

- search - aimed at identifying problems and finding ways to solve them.

The following features are also used as the basis for classifying business training games: - degree of formalization of the procedure ("fixed" and "free" games);

- presence or absence of conflict in the scenario (business games in cooperative situations, conflict situations with non-strict rivalry, in conflict situations with strict rivalry);

- the level of problematic character (the first level involves the detection and formulation of problems that require resolution in the analysis of a specific game situation, the second level is characterized by the involvement of students in co-reflection, in an active search for ways and means to solve the questions posed;

- degree of participation of students in the preparation of business games (games with and without home training);

- duration of the game procedure (mini-games lasting several minutes or lasting several days);

- nature of the simulated situations (playing with an opponent, with nature, learning game);

- nature of the game process: games with and without interaction of participants;

- method of transmitting and processing information (using texts, computers, etc);

- dynamics of simulated processes (games with a limited number of moves, unlimited, selfdeveloping);

- thematic focus and the nature of the problems to be solved (thematic games - focused on making decisions on narrow problems; functional games - simulating the implementation of individual functions or management procedures; complex games - simulating the management of a particular object or process as a whole [2].

Now we need to understand how to implement gamification in the internal environment of the enterprise in order to get the maximum benefit and feedback from employees. At first, you might think that such a tool can be easily implemented in an organization, but, unfortunately, this is a misconception.

As in any game, players can be divided into groups, so before using gamification, the manager should study his/her team and mentally divide it into types of "gamers". You can address to various methods, ranging from routine observation to the compilation of questionnaires.

Descriptions of "gamers" are very similar to descriptions of temperaments, psychological roles, and types of people; this fact is not surprising, because these types are really closely related, since the main focus of this tool is to increase employee motivation and improve the psychological climate. It is also important to keep in mind that a pure type is rarely to find, in fact, each person is a mixture of several types that can transform depending on the conditions. 
The typology of players was formulated by Andrzej Marczewski, an expert in the field of gamification:

1. A player is a person who can be motivated by external rewards. They are interested in the game process itself and the rewards for winning. For the sake of rewards, they do everything that is required of them.

2. A communicator is a person for whom the most important factor of action is the ability to create a close connection with the team, as well as social status, which makes it possible to find and get to know more people with similar interests and meet the need for communication. They like to feel a kinship with the team.

3. A creator is a person who prefers research, independence and freedom from the rules, so it is important to remember that you should not limit their craving for creativity and customization (changing something with the help of various design solutions).

4. An achiever is a person whose motive is professionalism in the chosen field. They like to set themselves almost impossible tasks and insurmountable obstacles, because they get pleasure from passing. They do not brag about their success, they do everything for themselves, only in certain cases they look at the ratings, because it is important for them to be the best.

5. A philanthropist is a person who lives for a global goal. They are altruistic and like to feel involved in something great, as well as to help other people; it also makes them feel needed, so they do not need additional rewards.

6. Violator (destroyer) - a person who tends to changes, no matter positive or negative. They want to destroy the entire system, simply because they can, resorting to any methods, for example, hacking the system, looking for loopholes in the rules, even with the help of other players, the main thing is to create new impressions and satisfy curiosity.

The first five types enjoy participating in the game (especially type number one), while the violators do not want to have anything to do with it and seek to break the technology [3].

In general, the task of the manager is to give people exactly the "prize" that they want to get and that will make them work more, while one must not forget about the relationships in the teams themselves.

Thus, summarizing all of the above, we can give the following recommendations for the introduction of elements of gamification in the organization.

First, it is necessary not only to study the directions of using the game in a non-game context, but also to study in detail the issue of organizational changes associated with the introduction of gamification, analyze the process of transforming existing systems into gaming systems, and identify the factors that affect the effectiveness of this transformation. Accordingly, the issues of restructuring the thinking of managers and employees of the company, understanding the organizational gaming experience of employees, in order to determine the most effective gaming techniques and elements, become relevant. It is necessary to develop effective methods for transferring the knowledge and gaming experience of employees obtained in the field of leisure to solving business problems. In this regard, the question is that the game design should be user-oriented, and not only technically-centered.

Secondly, the use of gamification requires an understanding of human psychology, as well as knowledge and skills in applying specific game methods and techniques in a nongame context. Therefore, in the near future, companies will need managers with the appropriate competencies. However, in the Russian higher education system, the inclusion of gamification courses in management training programs is the exception rather than the rule.

Third, company management must recognize that gamification brings the greatest benefits if it is built around the long-term values and goals of the organization. Therefore, 
all gamification projects must be consistent with the organization's development strategy and corporate brand values.

If we talk about the use of gamification, it should be noted that it is used in absolutely any organization, regardless of the type of activity and the number of employees. The difficulty lies in how to implement and what virtual elements of the game to apply. Also, certain difficulties may arise with understanding people: many are accustomed to perceiving games as a child's pastime, for this reason it is important to correctly convey the idea and show not only the seriousness, but also the effectiveness of the methodology, also taking into account the organizational culture and standards. The game network or applications should not look like an alien element but should fit harmoniously into the existing order of things.

It is important to remember that the introduction of gaming networks and applications is not final, but it's rather the beginning, because it is necessary to pay attention to the reaction of employees and further monitor it, periodically, if necessary, make adjustments and improve the mechanics, although the latter will always be relevant. It can also be noted that encouraging gambling addictions in organizations, can lead to negative results, in particular, to loss of productivity.

When creating an internal social network, it should be borne in mind that it should not be left without the attention of a responsible person who directs activities within this network, acts as an example, and explains the goals of creating this environment and its main tasks. The same game gets boring over time, as the player begins to gravitate towards changes, whether they are positive or negative, then towards destroying the entire system by resorting to any methods, for example, hacking, finding loopholes in the rules, even through other players, the main thing is to get new impressions and satisfy curiosity [4].

Here are some examples in the Russian Federation. The most famous, perhaps, is the company "KROK "(CJSC" KROK incorporated" - a Russian system integrator, one of the ten largest IT companies in Russia), which uses a social network on the Jive platform. Thanks to it, employees have the opportunity to gather in groups and work on projects and simultaneously communicate with customers, but the main advantage of the platform is access to a database of professional data.

Unfortunately, such a powerful and effective method as the introduction of interactivity in the business sphere and in personnel management is not very popular not only in Russia, but also around the world. If we look at the figures, it turns out that about $77 \%$ of entrepreneurs not only haven't tried to use gamification methods but have not even heard about it. In the case of using this method, the result is far from ideal, and projects are doomed to failure in advance, or the potential is not fully realized, respectively, labor productivity does not grow too quickly, and relations in the team remain at the same level.

Naturally, one might think that all these problems are only local and occur only in small firms, large organizations cannot make mistakes, but in fact, the inability of small companies gradually develops into larger problems and leads to difficulties in ordinary business, which in the future can affect absolutely every employee [4].

Now we should get to the point - the process of implementing gamification. This action should be done as follows:

1) Identification of the problem of the organization and, consequently, the formulation of the main goal of the introduction of gamification;

2) Dividing the goal into tasks using SMART technology (concreteness, measurability, achievability, relevance, time limitation);

3) Determining the type of game;

4) Creating game mechanics and basic rules;

5) Search for performers;

6) Application development; 
7) Direct implementation;

8) Control.

Thus, managers and employees should study and understand this methodology in detail before trying to implement it in their workplace, one does not need to rush and chase an instant result and expect visible improvements immediately but need to be patient and be ready for constant improvements and innovations [5].

Summarizing all the above, we can conclude that the gamification method, which appeared relatively recently, but is not gaining fast popularity among organizations, despite its effectiveness, so it can negatively affect their work. For this reason, recommendations were made aimed at solving the problem of introducing gamification and increasing the level of staff involvement. It is obvious that the action plan will not give instant results, but it is necessary to start acting. Thus, the company can attract employees and customers to the game process, which will ultimately lead to an improvement in financial indicators and psychological health of people.

\section{References}

1. N. I. Arkhipova, S. V. Nazaykinsky, O. L. Sedova, Sovremennyye problemy upravleniya personalom, Monografiya, (Prospect, 156, 2018)

2. S. A. Gabrusevich, G. A. Zorina, Ot delovoy igry - k professionalnomu Interesu, (Minsk: Universitetskoe, 125, 1989)

3. A. Marczewski, Game Thinking. Even Ninja Monkeys Like to Play: Gamification, Game Thinking and Motivational Design (Publ. Blurb, 2015)

4. A. N. Sokolova, HR-services in Russia: market overview, [Online], https://rb.ru/story/HR-tech-present/ [Accessed: 01 March 2021]

5. V.S. Kanivets, N. Yu. Donets Geymifikatsiya v upravlenii personalom organizatsii, VESTNIK studencheskogo nauchnogo obshchestva, 10(3), 55-56 (2019) 